\title{
Bamboo Spine in Ankylosing Spondylitis is at Increased Risk of Fracture
}

\section{Beaven A*, Fan J and Gardner A}

Department of Spinal Surgery, The Royal Orthopaedic Hospital Birmingham, The Woodlands, Bristol Road South, Birmingham, UK

${ }^{*}$ Corresponding author: Alstair Beaven, Department of Spinal Surgery, The Royal Orthopaedic Hospital Birmingham, The Woodlands, Bristol Road South, Birmingham, B31 2AP, UK, Tel: +44 121685 4000; E-mail: Alastairbeaven@traumaresearch.uk

Rec date: November 28, 2018; Acc date: January 2, 2019; Pub date: January 5, 2019

Citation: Beaven A, Fan J, Gardner A (2019) Bamboo Spine in Ankylosing Spondylitis is at Increased Risk of Fracture. Spine Res Vol.4 No.2:5.

\section{Abstract}

We present a case of missed spinal injury in a patient with ankylosing spondylitis that led to severe consequences for the patient. We present a radiograph showing a classic appearance of "bamboo spine", and subsequent MRI showing a three-column fracture. Bamboo spine occurs when the intervertebral discs ossify; this decreases flexibility and significantly increases the likelihood of spinal fracture with low energy mechanisms of injury. The mechanism of injury in this case was a fall from standing height which ultimately resulted in a severe spinal fracture with paraplegia. The absence of a fracture on radiographs in patients that have ankylosing spondylitis does not eliminate the presence of a fracture, and CT and MRI may well be indicated to confirm that there is no bony injury. We would like to highlight the importance of maintaining a high index of suspicion for patients who cannot give complete histories. The radiological appearance of bamboo spine should sharpen the clinical judgement of all who encounter it.

Keywords: Chance; Ossified discs; Paraplegia; Thoracolumbar instrumentation; Missed injury

\section{Introduction}

We present a case of missed spinal injury in someone with ankylosing spondylitis that led to severe consequences for the patient. We are of the opinion that diligence should be exercised when assessing this patient group and feel the presented case highlights the importance of enough radiological assessment.

The aim of our case study is to remind clinicians that patients with ankylosing spinal conditions may suffer significant injury from innocuous sounding mechanisms.

\section{Case Description}

A 60-year-old gentleman was assessed in a District General (non-specialist) Hospital Emergency Department (ED) three days after an unwitnessed fall from standing in his care home. He had a past medical history of profound learning disability, cerebral palsy, epilepsy and ankylosing spondylitis, and was usually independently mobile indoors. Observations in ED were: heart rate $89 \mathrm{bpm}$, respiratory rate $18 \mathrm{bpm}$, blood pressure $136 / 83, \mathrm{Temp}-37^{\circ} \mathrm{C}$.

The reason for ED attendance was reluctance to mobilize. The history was said to be challenging to obtain, and the patient complained of bilateral hip pain. Examination of his hip joints shown no deformity, tenderness, swelling or bruising and there was full passive movement of hips, knees and ankles.

Radiographs of the lumbar spine showed a bamboo spine appearance [1] a late sign in keeping with ankylosing spondylitis (Figure 1 ) and pelvic radiography revealed no abnormality.

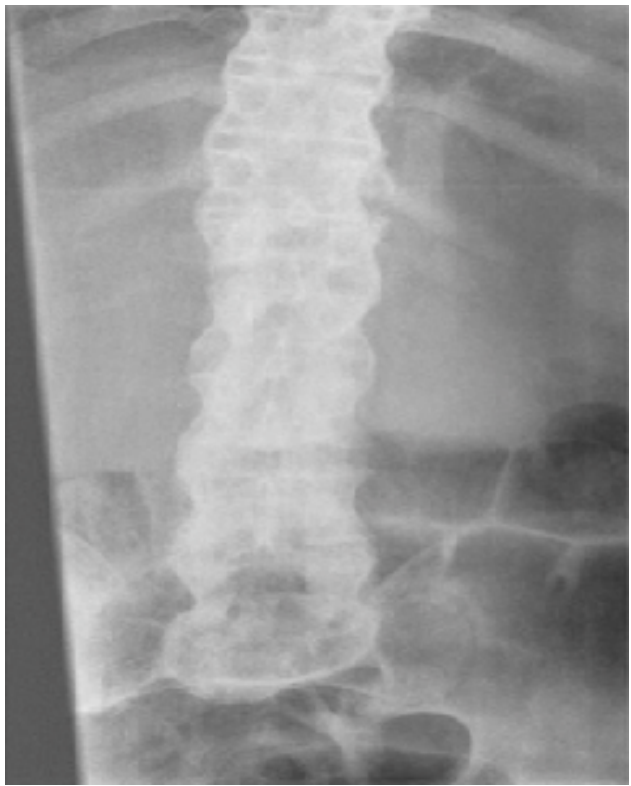

Figure 1: Plain film radiograph showing bamboo spine appearance with ossification of intervertebral discs.

The patient could not mobilize due to pain, so a CT of the pelvis was performed, again revealing no abnormality, and he was admitted for rehabilitation. As part of his treatment he was transferred to a rehabilitation center the day after admission where they noticed that he had developed double incontinence. A day later he developed paraplegia, and an 
urgent MRI was performed. This showed a highly unstable "Chance" type 3 column fracture [2] at T12/L1 ossified disc space (Figure 2).

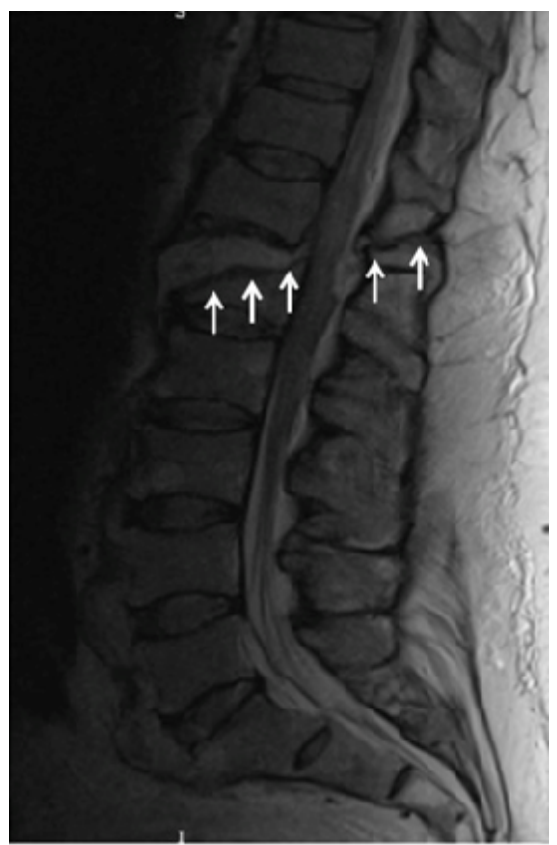

Figure 2: Sagittal MRI showing unstable fracture at thoracolumbar junction (white arrows illustrate anterior and posterior elements of fracture).

He was transferred to a regional spinal specialist Centre, and after discussion with his next of kin, underwent thoracolumbar instrumentation to prevent deterioration of neurological function. Unfortunately, his neurology has not recovered, and he requires full nursing care.

\section{Discussion and Conclusion}

It is noted that patients with spinal ankylosing disorders are particularly susceptible to injury with only minimal trauma, and injuries are not always noticed expediently [3]. Delays to diagnosis (of vertebral fracture) and secondary neurological injury have unfortunately been reported historically [4] and continue to occur, such as in the presented case.

Inflammation and osteo-proliferation contribute to the characteristic features of ankylosing spondylitis; namely stiffness and lack of spinal mobility [5]. It is this stiffness that is predominantly responsible for fracture, as whilst the rate of spinal fractures is increased in patients with ankylosing spondylitis, the rate of limb fractures is not [6].

We would like to remind clinicians of the special care needed when assessing patients with ankylosing spondylitis and identify the following important points;

- The index of suspicion for patients who cannot give complete histories should be high with imaging investigations to rule out unreported injury.

- Bamboo spine occurs when the intervertebral discs ossify seen in ankylosing spondylitis and similar conditions; this decreases flexibility and significantly increases the likelihood of a spinal fracture with low energy mechanisms of injury.

- In ankylosing spondylitis, a full imaging assessment of the spine should be performed in all cases of painful traumatic injury that cause inability to mobilize no matter how insignificant the mechanism appears to be. The absence of a fracture on radiographs does not eliminate the presence of a fracture, and CT and MRI are then indicated to confirm that there is no bony injury.

\section{References}

1. Yasin Y, Perumpillichira J, Dyer RB (2016) Classics in abdominal imaging: The bamboo spine. Abdom Radiol 41: 2078-2079.

2. Chance GQ (1948) Note on a type of flexion fracture of the spine. Brit j radiol 21: 452-453.

3. Rustagi T, Drazin D, Oner C, York J, Schroeder GD, et al. (2017) Fractures in spinal ankylosing disorders: a narrative review of disease and injury types, treatment techniques, and outcomes. J Orthop Trauma 1: 57-74.

4. Finkelstein JA, Chapman JR, Mirza S (1999) Occult vertebral fractures in ankylosing spondylitis. Spinal Cord 37: 444.

5. Wanders A, Landewe R, Dougados M, Mielants H (2005) Association between radiographic damage of the spine and spinal mobility for individual patients with ankylosing spondylitis: can assessment of spinal mobility be a proxy for radiographic evaluation? Ann Rheum Dis 64: 988-994.

6. Cooper C, Carbone L, Michet CJ, Atkinson EJ, O'Fallon WM (1994) Fracture risk in patients with ankylosing spondylitis: A population-based study. J Rheumatol 21: 1877-1882. 